\title{
Time variations of the ionosphere at the northern tropical crest of ionization at Phu Thuy, Vietnam
}

\author{
H. Pham Thi Thu ${ }^{1,2}$, C. Amory-Mazaudier ${ }^{1}$, and M. Le Huy ${ }^{2}$ \\ ${ }^{1}$ LPP/UPMC/Polytechnique/CNRS, UMR 7648, 4 Avenue de Neptune 94107 Saint-Maur-des-Fossés, France \\ ${ }^{2}$ Institute of Geophysics, Vietnam Academy of Science and Technology, A8, 18 Hoang Quoc Viet str. Cau Giay, Hanoi, \\ Vietnam
}

Received: 6 May 2010 - Revised: 4 January 2011 - Accepted: 13 January 2011 - Published: 26 January 2011

\begin{abstract}
This study is the first which gives the climatology of the ionosphere at the northern tropical crest of ionization in the Asian sector. We use the data from Phu Thuy station, in Vietnam, through three solar cycles (20, 21 and 22), showing the complete morphology of ionosphere parameters by analyzing long term variation, solar cycle variation and geomagnetic activity effects, seasonal evolution and diurnal development. Ionospheric critical frequencies, $f o \mathrm{~F} 2, f o \mathrm{~F} 1$ and $f o \mathrm{E}$, evolve according to the 11-year sunspot cycle. Seasonal variations show that $f o \mathrm{~F} 2$ exhibits a semiannual pattern with maxima at equinox, and winter and equinoctial anomalies depending on the phases of the sunspot solar cycle. $\Delta f o \mathrm{~F} 2$ exhibits a semiannual variation during the minimum phase of the sunspot solar cycle 20 and the increasing and decreasing phases of solar cycle 20,21 and 22. $\Delta f o \mathrm{~F} 1$ exhibits an annual variation during the maximum phase of solar cycles 20, 21 and 22. $\Delta h^{\prime} \mathrm{F} 2$ shows a regular seasonal variation for the different solar cycles while $\Delta h^{\prime} \mathrm{F} 1$ exhibits a large magnitude dispersion from one sunspot cycle to another. The long term variations consist in an increase of $1.0 \mathrm{MHz}$ for $f o \mathrm{~F} 2$ and of $0.36 \mathrm{MHz}$ for $f o \mathrm{~F} 1$. $f o \mathrm{E}$ increases $0.53 \mathrm{MHz}$ from solar cycle 20 to solar cycle 21 and then decreases $-0.23 \mathrm{MHz}$ during the decreasing phase of cycle 21 . The diurnal variation of the critical frequency $f o \mathrm{~F} 2$ shows minima at 05:00 LT and maxima around 14:00 LT. $f o \mathrm{~F} 1$ and $f o \mathrm{E}$ have a maximum around noon. The diurnal variation of $h^{\prime} \mathrm{F} 2$ exhibits a maximum around noon. The main features of $h^{\prime} \mathrm{F} 1$ are a minimum near noon and the maximum near midnight. Other minima and maxima occur in the morning, at about 04:00 or 05:00 LT and in the afternoon, at about 18:00 or 19:00 LT but they are markedly smaller. Only during the maximum phase of all sunspot solar cycles the maximum near 19:00 LT is more pronounced.
\end{abstract}

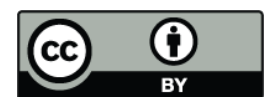

Correspondence to: H. Pham Thi Thu (hong.phamthithu@lpp.polytechnique.fr)
Keywords. Ionosphere (Equatorial ionosphere; Ionization mechanisms; Ionosphere-atmosphere interactions)

\section{Introduction}

Since the first ionosonde sounding in 1925 (Breit and Tuve, 1926), large data bases of ionosonde data covering several sunspot solar cycles were built. It is now possible to analyze several different time variation patterns of the ionosphere: long term, sunspot solar cycles, annual and diurnal. The present work gives a general description of ionospheric layers variations at Phu Thuy, a station located at the northern crest of ionization in the Asian sector.

The different time variations of the ionosphere have been studied by various authors.

- The long term variations observed by ionosonde located in different regions were previously analyzed by Elias and Ortiz de Adler (2006), Bremer (2008) and Ouattara et al. (2009). Three factors were proposed to explain the long term variation (Lastovicka et al., 2006; Elias, 2009): (1) green house gases (Bremer, 2008), (2) changes in the Earth's magnetic field (Elias and Ortiz de Adler, 2006; Cnossen and Richmond, 2008) and (3) geomagnetic activity. Concerning the solar cycle variation, it is well known that ionization of the ionospheric layers is controlled by solar UV and EUV radiations which follow the solar sunspot cycle (Rishbeth and Gariott, 1969).

- The F2 layer semiannual pattern with equinoctial and winter asymmetries was previously observed. Three mechanisms were proposed to explain these observations: (1) the seasonal change of the ratio $\mathrm{O} / \mathrm{N} 2$ (Rishbeth and Setty, 1961), (2) the Sun Earth distance (Yonezawa, 1959; Rishbeth et al., 2000a), and (3) waves

Published by Copernicus Publications on behalf of the European Geosciences Union. 
Table 1. Years of the different solar cycle phases.

\begin{tabular}{ccccc}
\hline Cycles & $\begin{array}{c}\text { Minimum } \\
\text { phase }\end{array}$ & $\begin{array}{c}\text { Increasing } \\
\text { phase }\end{array}$ & $\begin{array}{c}\text { Maximum } \\
\text { phase }\end{array}$ & $\begin{array}{c}\text { Decreasing } \\
\text { phase }\end{array}$ \\
\hline 20 & 1964 & $1965-1966$ & $1968-1970$ & $1971-1975$ \\
21 & 1976 & $1977-1978$ & $1979-1980$ & $1982-1985$ \\
22 & 1986 & $1987-1988$ & $1989-1991$ & $1992-1995$ \\
\hline
\end{tabular}

and tides transmitted from the low thermosphere (Zou et al., 2000).

- The variations of the F1 layer, the transition layer between the E and F2 layers, are explained by the combination of F2 and $\mathrm{E}$ layers variations, related to photochemical rates and changes in atmospheric composition or temperature (Rishbeth and Kervin, 1968).

We analyze data recorded since 1962. The paper is organized in several sections. The second section presents the data set and data analysis. Sections 3, 4 and 5 are, respectively, devoted to the long term and solar sunspot cycle variations, yearly and diurnal variations. Then we discuss our results and conclude in Sect. 6.

\section{Data set and data analysis}

In this paper we analyze the critical frequencies and virtual heights of the ionospheric layers F2, F1, E, Es recorded by the ionosonde of Phu Thuy-Vietnam during the period from 1962 to 2002 (solar cycles 20, 21, 22). Phu Thuy station is located near the crest of equatorial anomaly $\left(10.2^{\circ} \mathrm{N} 108^{\circ} \mathrm{E}\right)$ in the Asian sector. We use hourly values at full hours of critical frequencies $f o \mathrm{~F} 2, f o \mathrm{~F} 1, f o \mathrm{E}$ and $f o \mathrm{Es}$ and virtual heights $h^{\prime} \mathrm{F} 2, h^{\prime} \mathrm{F} 1, h^{\prime} \mathrm{E}, h^{\prime} \mathrm{Es}$.

The ionosonde data were continuously recorded by three different ionospheric vertical sounders: the IRX-Hungarian (1962-1966), the AIC-Russian (1967-1994), the IPS71Australian (1994-2002).

In this study, we analyze long term variations, solar cycle, seasonal and diurnal variations of the ionospheric parameters for different magnetic activity given by the am index: magnetically quiet days with am $<20$ and disturbed days with am $\geq 20$.

- Arithmetical mean values obtained from day-time hourly values of parameters are used for studying diurnal variation. The daily mean values have been derived from the available hourly data (for foF2 and $h^{\prime} \mathrm{F} 1$ with maximal 24, for the other with maximal 13 values).

- Seasonal variation and yearly variation is obtained by using respectively arithmetical mean values of monthly and yearly values.
- Our seasons are the following: winter (November, December, January, and February), summer (May, June, July, August), autumn (September, October), spring (March, April). Error bars $(\sigma=\sqrt{V}, V$ : variance is given by $\frac{1}{N} \sum_{i=1}^{N}\left(x_{i}-\mu\right)^{2}$, where $\mu$ is the mean value) provide an estimation of the uncertainty in the ionospheric parameters.

- The study is performed for the different phases of solar cycles. We distinguish four parts: the minimum phase, years with $\mathrm{Rz}<20$, the increasing phase, years with $20 \leq \mathrm{Rz} \leq 100$, the maximum phase, years with $\mathrm{Rz}>100$ and the decreasing phase, years with $100 \geq$ $\mathrm{Rz} \geq 20$. Table 1 gives the years for each sunspot cycle phases.

\section{Solar cycle and long term variations}

Figure 1 illustrates the solar cycle variation of critical frequencies and virtual heights of ionospheric layers F2, F1, E and Es, during sunspot cycles 20, 21, 22. On the left side are shown the critical frequencies. On the right side are drawn the virtual heights. The panels from the top to bottom correspond respectively to $\mathrm{F} 2, \mathrm{~F} 1, \mathrm{E}$ and Es layers. On each panel is superimposed the yearly mean value of the sunspot number.

Figure 1 shows a good correlation between the critical frequency of F2 layer (foF2), F1 layer ( $f o \mathrm{~F} 1)$ and $\mathrm{E}$ layer $(f o \mathrm{E})$ and the sunspot cycle. On the contrary, the critical frequency of the Es layer ( $f o \mathrm{Es}$ ) and the virtual heights $h^{\prime} \mathrm{F} 2, h^{\prime} \mathrm{F} 1$, $h^{\prime} \mathrm{E}$ and $h^{\prime} \mathrm{Es}$ are poorly correlated with the sunspot number. From 1980 to 1994 , due to technical reasons, the virtual heights $h^{\prime} \mathrm{E}$ and $h^{\prime} \mathrm{Es}$ are not reliable and are not plotted on Fig. 1 .

Figure 1 also shows a long term variations of the critical frequencies $f o \mathrm{~F} 2$ and $f o \mathrm{~F} 1$ which are increasing through the 3 solar cycles. The critical frequency foE exhibits another pattern: it increases from 1962 until 1984 and decreases after. These observations will be discussed later in Sect. 6 .

The long term variations are computed by using the linear regression technique:

$X_{t h}=a \cdot R_{z}+b$

where $\mathrm{Rz}$ is the sunspot number.

Then we estimate

$\Delta X_{i}=X_{i}-X_{t h}$

where $X_{i}$ correspond to observations of critical frequencies.

$\Delta f o \mathrm{E}, \Delta f o \mathrm{~F} 1$ and $\Delta f o \mathrm{~F} 2$ are plotted on Fig. 2. This figure highlights the following characteristics: (1) $\Delta f o \mathrm{~F} 2$ increases from 1962 to 2002 with a rate of $0.025 \mathrm{MHz}$ per year (bottom panel), (2) $\Delta f o \mathrm{~F} 1$ increases with a rate of $0.009 \mathrm{MHz}$ per year 

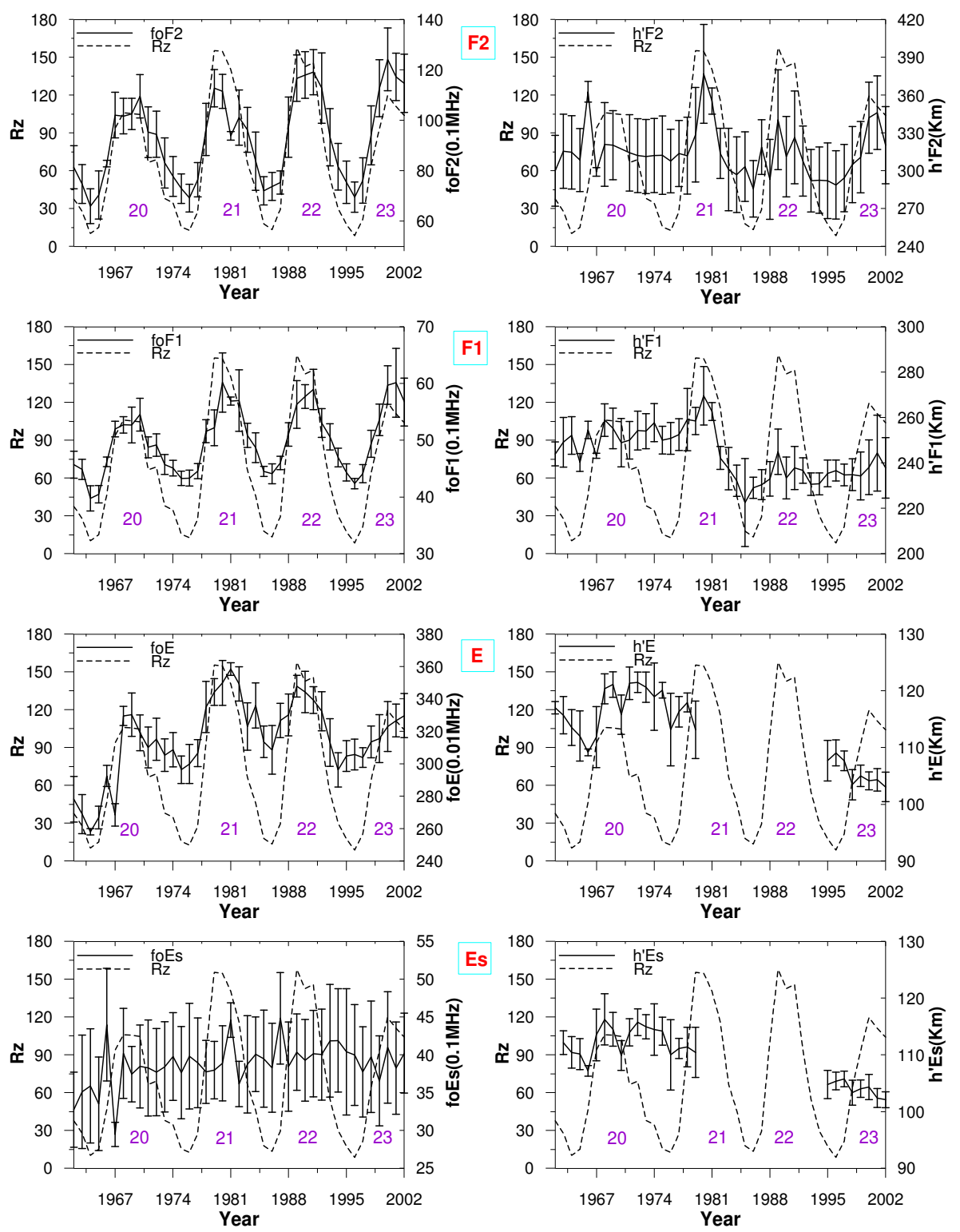

Fig. 1. Yearly variation of critical frequencies (left side) and virtual heights (right side) of the F2, F1, E and Es layers (solid line) and sunspot number (dashed line) during solar cycles 20, 21 and 22.

(middle panel) and (3) $\Delta f o \mathrm{E}$ increases from 1962 to 1982 with a rate of $0.024 \mathrm{MHz}$ per year and then decreases from 1984 to 2002 with a rate of $-0.013 \mathrm{MHz}$ per year (top panel).

Figure 3 presents, from the top to the bottom, the yearly variation of $f o \mathrm{~F} 2, h^{\prime} \mathrm{F} 2, f o \mathrm{~F} 1$ and $h^{\prime} \mathrm{F} 1$ during quiet days with am $<20$ (blue curve), during magnetically active days with $a m \geq 20$ (red curve) and for all the days (violet curve). This figure clearly shows that the geomagnetic effect is very small on the average values.

Tables 2 and 3 give the correlation coefficients between the ionospheric parameters and the $\mathrm{Rz}$ index for magnetic quiet days with am $<20$ (Table 2) and for all the days (Table 3 ). The correlation coefficients of $f o \mathrm{~F} 2$ during solar cycles 20 ,
21 and 22 are rather similar between 0.835 and 0.867 . There is no difference between the two samples with quiet days and all the days. Concerning the critical frequency $f o \mathrm{~F} 1$ the correlation coefficient decreases from solar cycle 20 to solar cycle 21 and increases for solar cycle 21 to solar cycle 22, both for quiet days (Table 2) and all the days (Table 3).

The correlation coefficient for $f o \mathrm{E}$ increases with solar cycle from 0.612 (cycle 20) to 0.754 (cycle 22) for the quiet days sample and from 0.611 to 0.739 for all the days. 
Table 2. Correlation coefficients between the ionospheric parameters and the sunspot number Rz during magnetically quiet days $(\mathrm{am}<20 \mathrm{nT})$.

\begin{tabular}{ccccc}
\hline Cycles/magnetic quiet days $(\mathrm{am}<20 \mathrm{nT})$ & 20 & 21 & 22 \\
\hline \multirow{6}{*}{ Correlation coefficients } & $f_{o} \mathrm{~F} 2$ & 0.836 & 0.847 & 0.842 \\
& $f_{o} \mathrm{~F} 1$ & 0.897 & 0.791 & 0.868 \\
& $h^{\prime} \mathrm{F} 2$ & 0.154 & 0.365 & 0.223 \\
& $h^{\prime} \mathrm{F} 1$ & 0.141 & 0.478 & 0.183 \\
& $f_{o} \mathrm{E}$ & 0.612 & 0.652 & 0.754 \\
& $f_{o} \mathrm{Es}$ & 0.0489 & 0.0762 & 0.001 \\
& $h^{\prime} \mathrm{E}$ & 0.213 & 0.297 & 0.005 \\
& $h^{\prime} \mathrm{Es}$ & 0.151 & 0.308 & 0.002 \\
\hline
\end{tabular}

Table 3. Correlation coefficients between the ionospheric parameters and the sunspot number Rz during all magnetically disturbed and quiet days with am $\geq 20 \mathrm{nT}$ and $\mathrm{am}<20 \mathrm{nT}$.

\begin{tabular}{ccccc}
\hline Cycles/all the days: magnetic quiet and disturbed & 20 & 21 & 22 \\
\hline & $f o \mathrm{~F} 2$ & 0.842 & 0.867 & 0.842 \\
$f o \mathrm{~F} 1$ & 0.913 & 0.725 & 0.895 \\
$h^{\prime} \mathrm{F} 2$ & 0.061 & 0.386 & 0.365 \\
& $h^{\prime} \mathrm{F} 1$ & 0.147 & 0.496 & 0.266 \\
Correlation coefficients & $f o \mathrm{E}$ & 0.611 & 0.745 & 0.739 \\
& $f o \mathrm{Es}$ & 0.038 & 0.087 & 0.010 \\
& $h^{\prime} \mathrm{E}$ & 0.245 & 0.330 & 0.005 \\
& $h^{\prime} \mathrm{Es}$ & 0.135 & 0.347 & 0.003 \\
\hline
\end{tabular}

\section{Seasonal variation}

In this section, for each month a mean regression equation $(X=a \mathrm{Rz}+b)$ has to be derived. Then by use of a constant value of $\mathrm{Rz}$ (can be zero or another value as e.g. the mean $\mathrm{Rz}$ value during the investigated time interval) for each month the corresponding ionospheric parameter $X(\mathrm{Rz})$ can easily be calculated. In these $X(\mathrm{Rz})$ data the solar influence is more or less eliminated. And then we analyze the seasonal variation $\Delta f o \mathrm{~F} 2, \Delta f o \mathrm{~F} 1, \Delta h^{\prime} \mathrm{F} 2, \Delta h^{\prime} \mathrm{F} 1$. Figure 4 illustrates the mean monthly variation of $\Delta f o \mathrm{~F} 2$ for the different sunspot phases: minimum phase (left upper panel), increasing phase (left bottom panel), maximum phase (right upper panel) and decreasing phase (right bottom panel). During all the phases, we clearly observe the semiannual variation of $\Delta f o \mathrm{~F} 2$ with highest values at equinox and minima at solstices. The first maximum arises in April, except during decreasing phase of solar cycle 22 . The second maximum appears generally in October.

We observe that the two equinox maxima are asymmetric: the autumnal maximum is smaller than the spring one during minimum and decreasing phases, whereas the spring maximum is smaller than the autumnal phase during increasing and maximum phase of the sunspot cycle 22. During the decreasing and maximum phases of solar cycles 21 and 22, the critical frequency $\Delta f o \mathrm{~F} 2$ in December is greater than in July.
Figure 5 is similar to Fig. 4 and shows the $\Delta f o \mathrm{~F} 1$ mean monthly variation for the four solar phases. There is no a regular seasonal behaviour through the solar phases. During the minimum phase of solar cycle 20 (left upper panel) the seasonal variation is similar to the $\Delta f o \mathrm{~F} 2$ one, i.e. it exhibits the two equinoctial maxima. During the maximum phase (top right panel), $\Delta f o \mathrm{~F} 1$ variation presents an annual behavior with a maximum in April for solar cycles 20 and 21 and a maximum in May for solar cycle 22. For the increasing and decreasing phases (bottom panels) $\Delta f o \mathrm{~F} 1$ exhibits a semiannual variation.

Figure 6 illustrates the seasonal variation of $\Delta h^{\prime} \mathrm{F} 2$. For all the sunspot cycle phases, $\Delta h^{\prime} \mathrm{F} 2$ is maximum in June and minimum in winter months. It increases during the beginning of the year from January to June and then decreases. $\Delta h^{\prime} \mathrm{F} 2$ changes with solar phases. During the minimum, increasing and decreasing phases, $\Delta h^{\prime} \mathrm{F} 2$ decreases from solar cycle 20 to solar cycle 21 (left upper panel and both bottom panels). On the contrary, during the maximum phases (right upper panel), $\Delta h^{\prime} \mathrm{F} 2$ is larger during solar cycle 21 than during the other solar cycles 20 and 22 .

Figure 7, similar to Fig. 6, presents seasonal variation of $\Delta h^{\prime} \mathrm{F} 1$, for the four solar cycle phases. The data show an annual variation with a maximum generally in June, and a minimum in winter. During the minimum, maximum and 

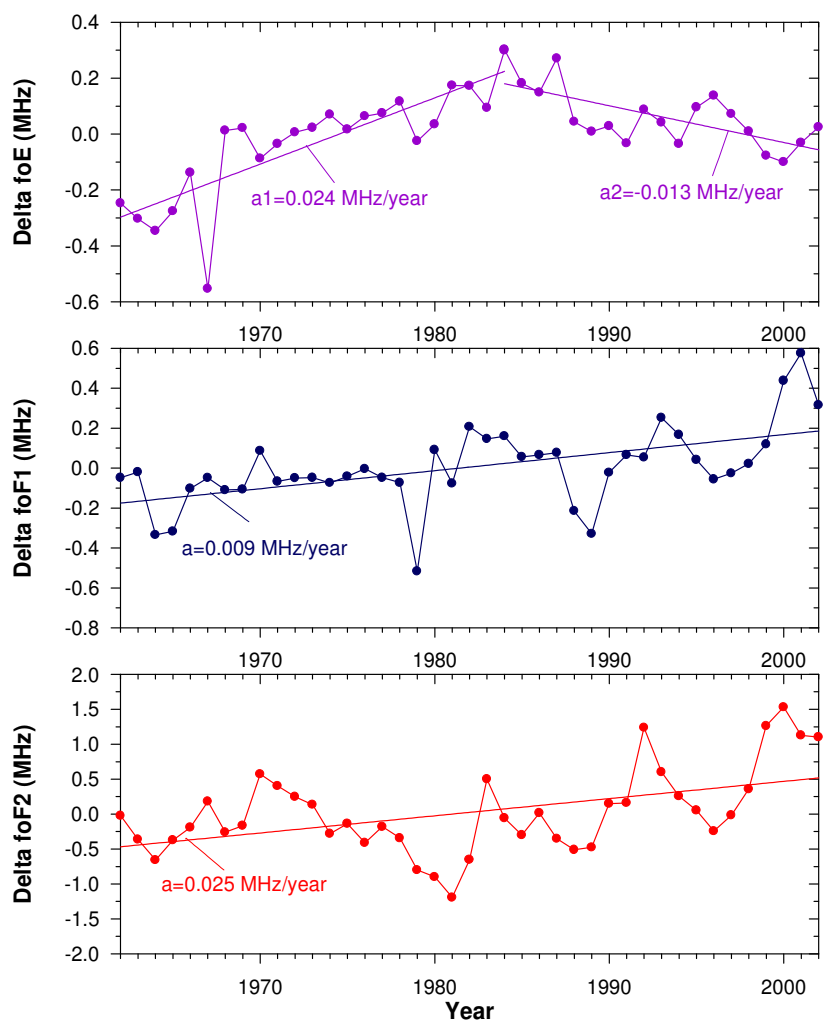

Fig. 2. Long-term trends of different ionospheric parameters $(f o \mathrm{~F} 2$, $f o \mathrm{~F} 1, f o \mathrm{E})$ observed at Phu Thuy after elimination of the solar influences $(\mathrm{Rz})$.

decreasing phases, $\Delta h^{\prime} \mathrm{F} 1$ presents rather similar variations for cycles 20, 21, 22.

During the increasing phase $\Delta h^{\prime} \mathrm{F} 1$ is rather the same for solar cycles 20 and 21.

\section{Diurnal variation}

Figure 8 shows the mean diurnal variation of $f o \mathrm{~F} 2$ observed during the different phases of the sunspot cycles, the red curve corresponds to cycle 20 , the blue one to cycle 21 and the violet one to cycle 22. foF 2 follows the same variation: before sunrise, $f o \mathrm{~F} 2$ decreases and is minimum at 05:00 LT. Then it increases to reach a maximum at 14:00 LT and decreases again later.

Figure 9 shows the mean diurnal variation of $f o \mathrm{~F} 1$, observed from 06:00 LT to 18.00LT, during all the phases of the sunspot cycles 20, 21, 22. foF1 increases from 06:00 LT to 12:00 LT and then symmetrically decreases. This pattern is observed for all the phases except for decreasing phases, during which the curves are different for different sunspot cycles (bottom right panel).

Figure 10 shows the mean diurnal variation of $h^{\prime} \mathrm{F} 2 \mathrm{ob}-$ served during daytime for the different phases of the sunspot cycles 20, 21 and 22. During all the phases of the sunspot
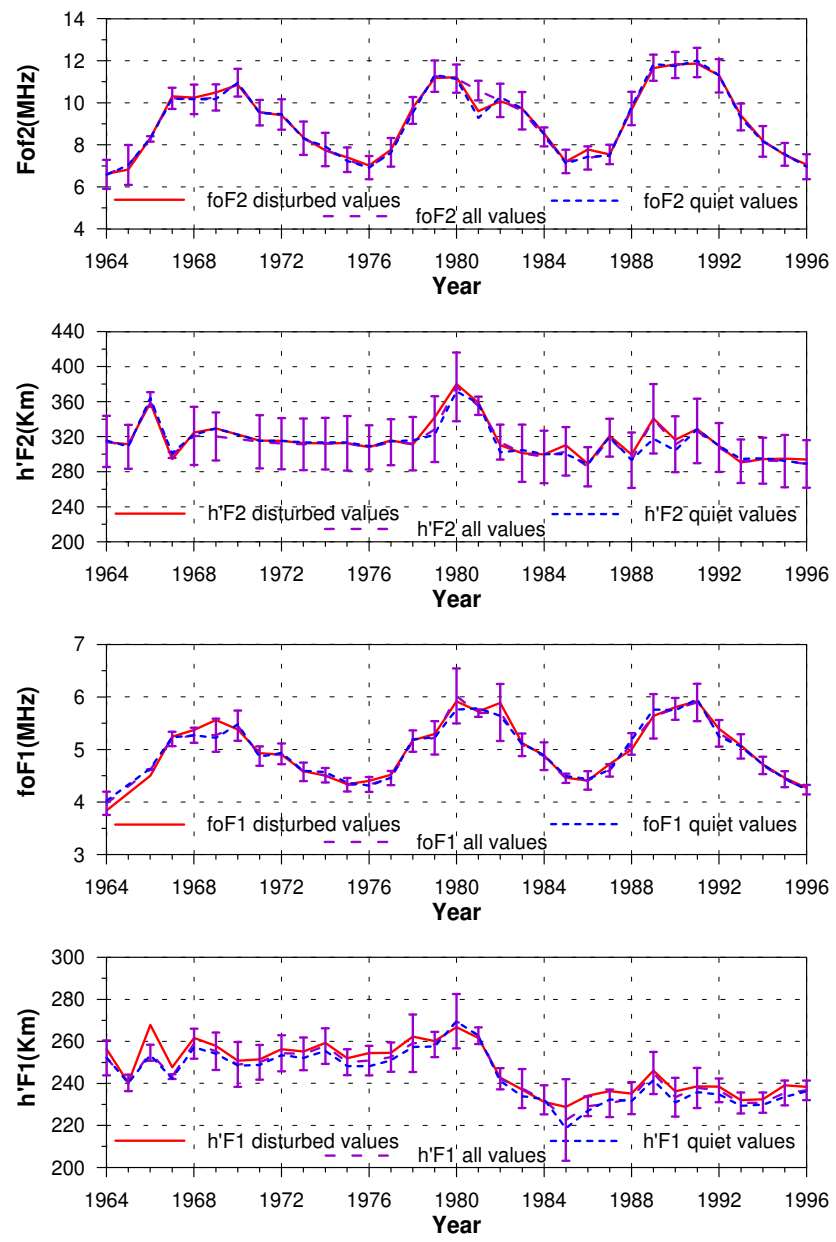

Fig. 3. Annual variation of $f o \mathrm{~F} 2, h^{\prime} \mathrm{F} 2, f o \mathrm{~F} 1$ and $h^{\prime} \mathrm{F} 1$ (from the top to the bottom), during solar cycles 20,21 and 22 . The red curves correspond to the magnetic disturbed days and the blue curves to the magnetic quiet days. The violet curves concern all the days.

cycles $h^{\prime} \mathrm{F} 2$ increases in the morning, is maximum at about 12:00 LT and decreases in the afternoon. The mean diurnal variation of $h^{\prime} \mathrm{F} 2$ varies from $260 \mathrm{~km}$ to $360 \mathrm{~km}$ in the daytime. $h^{\prime} \mathrm{F} 2$ is greater during daytime than during night time. This is a particular feature of the F-layer near the tropical crest of ionization. We also notice that the diurnal variation of $h^{\prime} \mathrm{F} 2$ is rather the same for all the phases of the sunspot cycle, but from one solar cycle to another the amplitude of the virtual height $h^{\prime} \mathrm{F} 2$ changes.

Figure 11 shows the mean diurnal variation of the virtual height $h^{\prime} \mathrm{F} 1$ for the different phases of sunspot cycles 20, 21 and 22. The main features are the minimum near noon and the maximum near midnight. Other minima and maxima occur in the morning, at about 04:00 or 05:00 LT and in the afternoon, at about 18:00 or 19:00 LT but they are markedly smaller here, except during the sunspot maximum (top right panel) where the afternoon maxima are greater than the night maxima for solar cycle 21 and 22 . 
Table 4. Characteristics of ionospheric parameters.

\begin{tabular}{|c|c|c|c|c|}
\hline & $\begin{array}{l}\text { Column } 1 \\
\text { Longterm variation }\end{array}$ & $\begin{array}{l}\text { Column } 2 \\
\text { Solar cycle }\end{array}$ & $\begin{array}{l}\text { Column } 3 \\
\text { Annual variation }\end{array}$ & $\begin{array}{l}\text { Column } 4 \\
\text { Diurnal variation }\end{array}$ \\
\hline$f_{o} \mathrm{~F} 2$ & $\begin{array}{l}\text { Increasing: } 1.0 \mathrm{MHz} \text { from } \\
1962 \text { to } 2002\end{array}$ & $\begin{array}{l}\text { Correlation } \\
0.842(20) \\
0.867(21) \\
0.842(22)\end{array}$ & $\begin{array}{l}\text { Semiannual } \\
\text { Equinoctial asymmetry } \\
\text { Winter anomaly: minimum } \\
\text { summer except solar cy- } \\
\text { cle } 20\end{array}$ & $\begin{array}{l}\text { Minimum } \\
\text { at 05:00 LT } \\
\text { Maximum } \\
\text { at 14:00 LT }\end{array}$ \\
\hline$f o \mathrm{~F} 1$ & $\begin{array}{l}\text { Increasing: } 0.36 \mathrm{MHz} \text { from } \\
1962 \text { to } 2002\end{array}$ & $\begin{array}{l}\text { Correlation } \\
0.913(20) \\
0.725(21) \\
0.895(22)\end{array}$ & $\begin{array}{l}\text { Annual during all maxi- } \\
\text { mum phases } \\
\text { Semiannual during the min- } \\
\text { imum phase of cycle } 20 \\
\text { Semiannual during } \\
\text { increasing and decreasing } \\
\text { phases all cycles }\end{array}$ & $\begin{array}{l}\text { Maximum } \\
\text { at 12:00 LT }\end{array}$ \\
\hline$f o \mathrm{E}$ & $\begin{array}{l}\text { Increasing } 0.53 \mathrm{MHz} \text { from } \\
1962 \text { to } 1983, \\
\text { Decreasing }-0.23 \mathrm{MHz} \\
\text { from } 1984 \text { to } 2002\end{array}$ & $\begin{array}{l}\text { Correlation } \\
0.611(20) \\
0.745(21) \\
0.739(22)\end{array}$ & & \\
\hline foEs & & No correlation & & \\
\hline$h^{\prime} \mathrm{F} 2$ & & No correlation & Annual variation & $\begin{array}{l}\text { Maximum } \\
\text { at 12:00 LT }\end{array}$ \\
\hline$h^{\prime} \mathrm{F} 1$ & $\begin{array}{l}\text { Decreasing: } 25 \mathrm{~km} \text { dur- } \\
\text { ing decreasing phase of cy- } \\
\text { cle } 21\end{array}$ & No correlation & Annual variation & $\begin{array}{l}\text { Maximum near 24:00 LT, } \\
\text { minimum near 12:00 LT, } \\
\text { additional secondary max- } \\
\text { ima near 05:00 LT and } \\
\text { 19:00 LT. }\end{array}$ \\
\hline
\end{tabular}

\section{Discussion and conclusion}

In Table 4 we recapitulate our main results. The columns correspond to the time scale variations of the data (long term, solar, annual and diurnal) and the rows to the ionospheric parameters (critical frequencies and virtual heights). We will analyze in detail the characteristics and properties of the ionospheric parameters for different time scales.

\subsection{Long term variations}

The critical frequencies $f o \mathrm{~F} 2$ and $f o \mathrm{~F} 1$ show a long-term increase of $1.0 \mathrm{MHz}$ and $0.36 \mathrm{MHz}$, respectively, during the period here analyzed. $f o \mathrm{E}$ increases by $0.53 \mathrm{MHz}$ from sunspot cycle 20 to 21 followed by a decrease of $-0.23 \mathrm{MHz}$.

Bremer (2008), explained the long term changes in the parameters of the E- and F1-regions by an increasing atmospheric greenhouse effect (increase of CO2). Bremer (2008) observed different long term variations from one station to another station.

Elias and Ortiz de Adler (2006) explained the long term changes in the amplitude of $f o \mathrm{~F} 2$ observed at Tucuman at the southern crest of the equatorial anomaly by the trend of the magnetic dip angle which increased during the analyzed 30 years interval with a rate of $0.35 \%$ year.

Mikhailov and Marin (2000, 2001), Mikhailov and Morena (2003), Mikhailov (2008), Elias and Ortiz de Adler (2006) explained the long term variations observed at mid and high latitudes in the Northern Hemisphere by geomagnetic activity effects. Finally three main factors must be considered: greenhouse gases, geomagnetic activity and Earth's magnetic field (Lastovicka et al., 2006; Elias, 2009).

Cnossen and Richmond (2008) modelled the effects of the changes in the Earth's magnetic field from 1957 to 1997 on the ionopsheric $h m \mathrm{~F} 2$ and $f o \mathrm{~F} 2$ data using model results from the TIEGCM. They can explain a variation of $h m \mathrm{~F} 2$ of $20 \mathrm{~km}$ and of $f o \mathrm{~F} 2$ of $0.5 \mathrm{MHz}$ over the atlantic Ocean and South America. These values are of the same order as the Phu Thuy observations in Asia.

In our case we observe similar long term variations of the F1- and F2-layers: increase of the critical frequencies. Concerning the E-layer the critical frequency increases and decreases. It is necessary to analyse more deeply the 

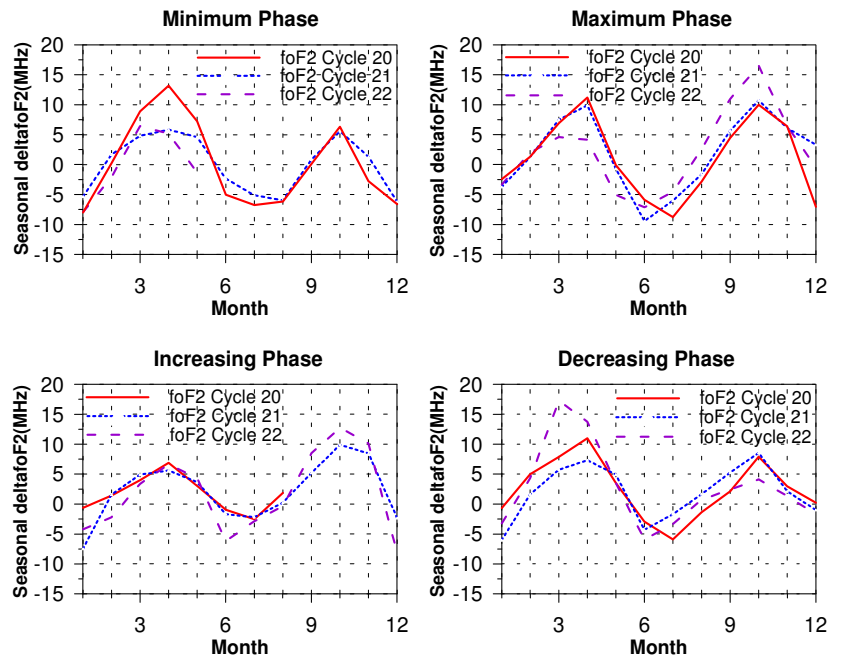

Fig. 4. Seasonal variation of the critical frequency $\Delta f o \mathrm{~F} 2$, after elimination of the solar influences $(\mathrm{Rz})$, during the various phases of the sunspot cycles: minimum phase (top left panel), increasing phase (bottom left panel), maximum phase (top right panel) and decreasing phase (bottom right panel). The red curves correspond to sunspot cycle 20, the dashed blue curves to sunspot cycle 21 and the violet curves to sunspot cycle 22 .
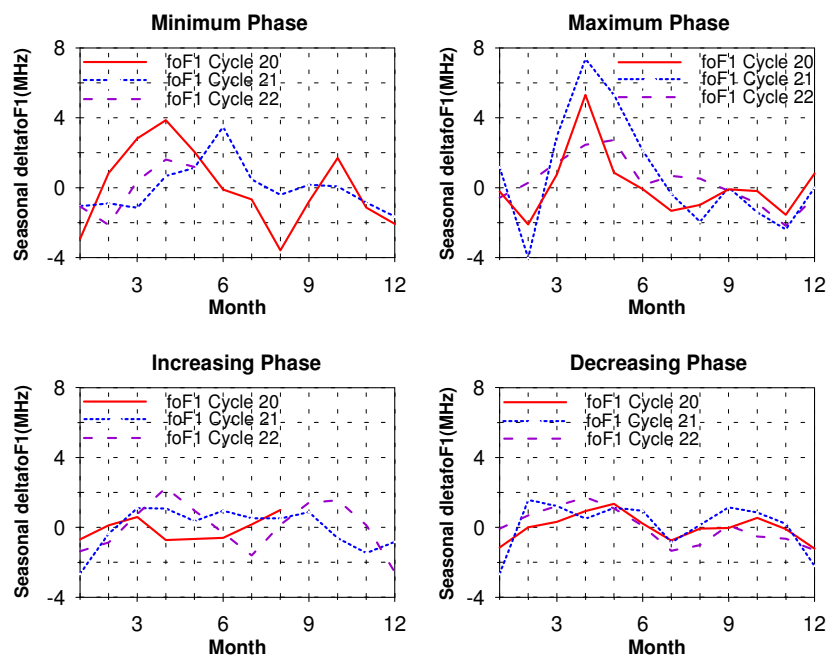

Fig. 5. Similar to Fig. 4 for $f o F 1$.

geophysical conditions at the northern crest of equatorial anomaly in the Asian sector which are different from the geophysical conditions in the European and American longitude sectors.

\subsection{Solar cycle variations}

In Table 4, column 2, there is given the evolution of the correlation coefficients of ionospheric parameters with sunspot number. The correlation coefficient is rather good for $f o \mathrm{~F} 2$, $f_{o} \mathrm{~F} 1$ and $f_{o} \mathrm{E}$, and less so for the $f_{o \mathrm{Es}}$ and virtual heights. Ta-
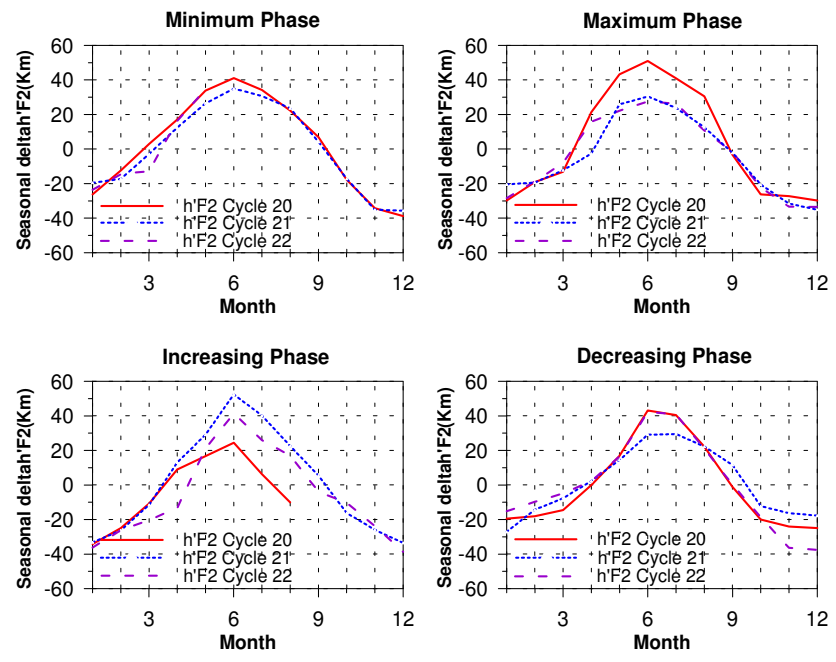

Fig. 6. Similar to Fig. 4 for $h^{\prime} \mathrm{F} 2$.
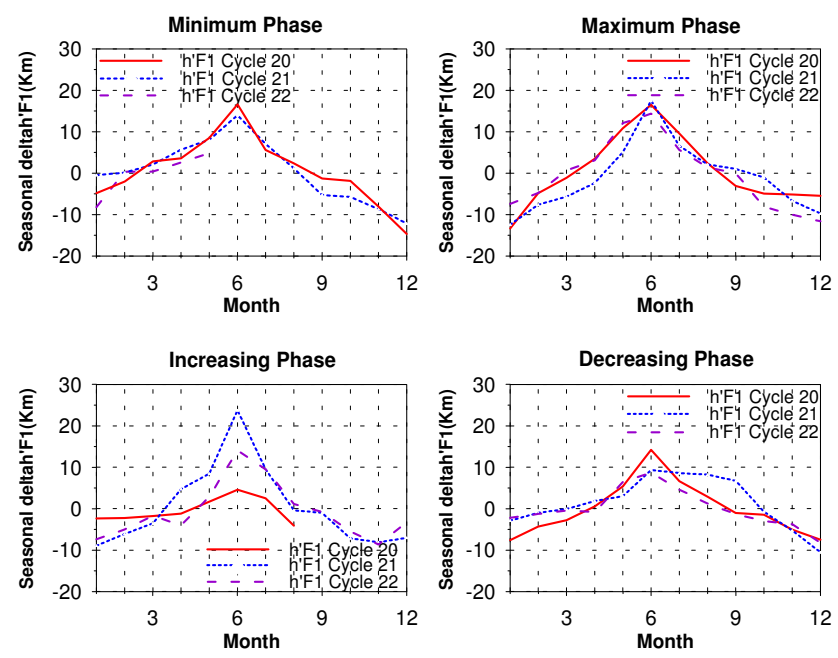

Fig. 7. Similar to Fig. 4 for $h^{\prime} \mathrm{F} 1$.

ble 5 gives the confidence intervals [99\% (column 3)] for the correlation between sunspot number $\mathrm{Rz}$ and $f o \mathrm{~F} 2, f o \mathrm{~F} 1, f o \mathrm{E}$. The correlation coefficients are statistically significant with 99\% confidence level by the Fisher's t-test.

The good correlation seen above is explained by the ionization of the Earth's atmosphere. The solar X-ray and extreme ultraviolet (EUV) radiation control the Chapman layers (Rishbeth and Gariott, 1969). The difference in the correlation coefficients from one sunspot cycle to another can be explained by changes in the solar cycle intensity (Balan et al., 1993).

Ouattara et al. (2009) found for Ouagadougou, located at the magnetic equator in the Northern Hemisphere, a good correlation between the sunspot number and $f_{o} \mathrm{~F} 2, f_{o} \mathrm{~F} 1$, and $h^{\prime} \mathrm{F} 1$, but no correlation for $f o \mathrm{E}, h^{\prime} \mathrm{F} 2$ and $h^{\prime} \mathrm{E}$. The absence of correlation between the sunspot number and $f o \mathrm{E}$ at the 

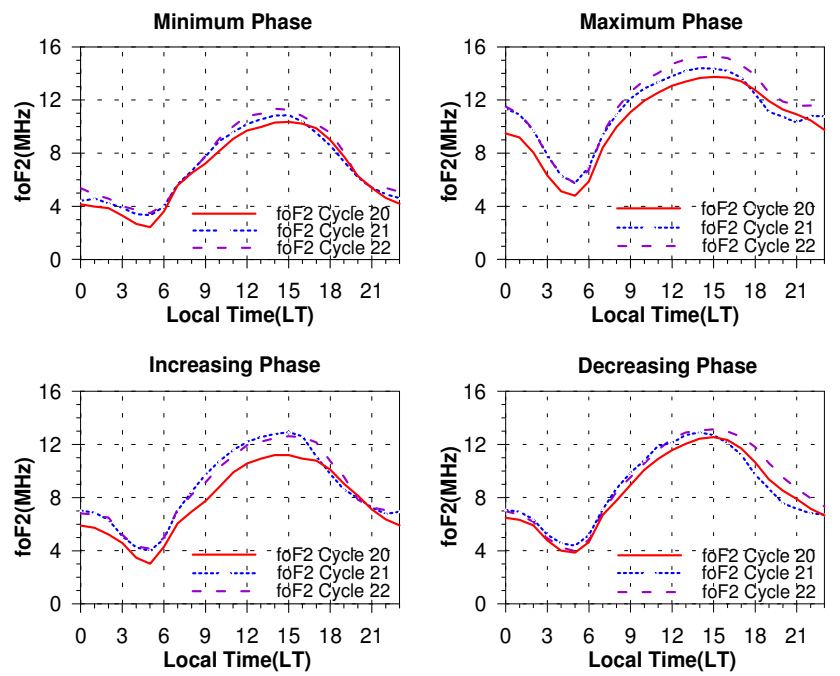

Fig. 8. Diurnal variation of the critical frequency foF 2 during minimum phase (left top panel), increasing phase (left bottom panel), maximum phase (right top panel) and decreasing phase (right bottom panel) for sunspot cycle 20 (red curves), sunspot cycle 21 (blue curves) and sunspot cycle 22 (violet curves).
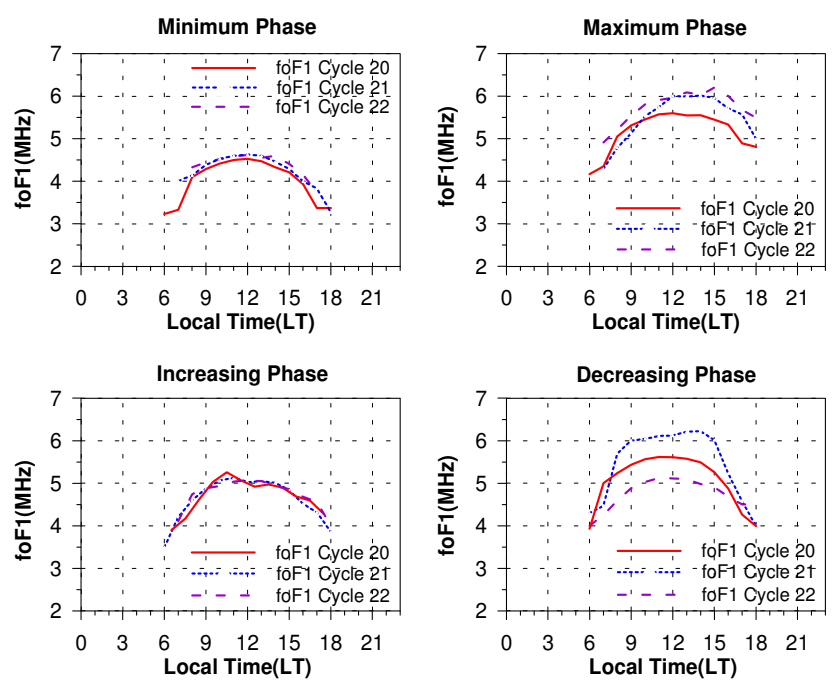

Fig. 9. Similar to Fig. 8 for $f o F 1$.

equator can be explained by the existence of the equatorial electrojet, which drives instabilities and generates strong plasma waves which strongly affect the electron density (Farley, 2009).

\subsection{Annual and semiannual variations}

The annual and semiannual variations of all layers are given in column 3 of Table $4 . \Delta f o \mathrm{~F} 2$ exhibits the well known equinoctial pattern with two maxima at the equinox (Fig. 4). But we observe also an asymmetry between the two maxima which changes with the phase of the sunspot cycle (row 1):
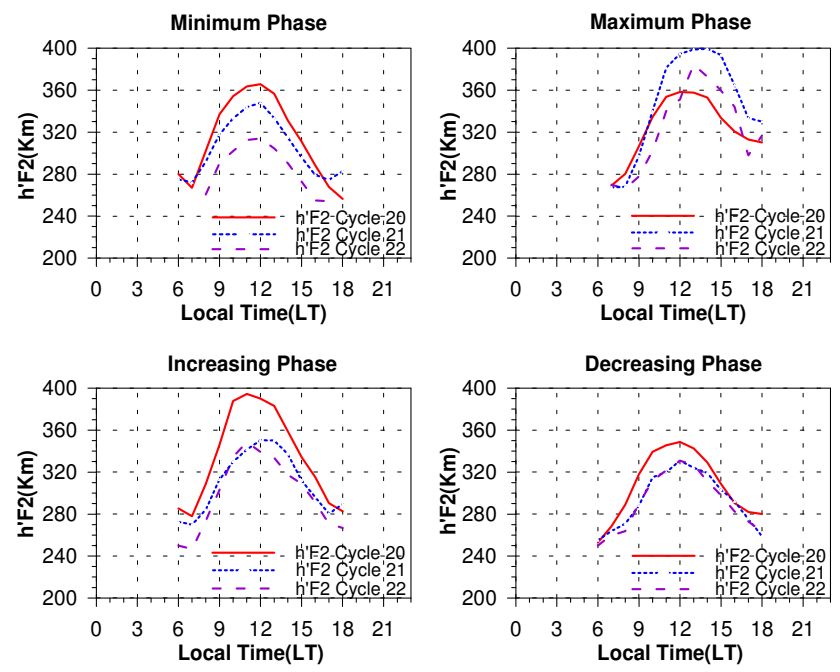

Fig. 10. Similar to Fig. 8 for $h^{\prime} \mathrm{F} 2$.
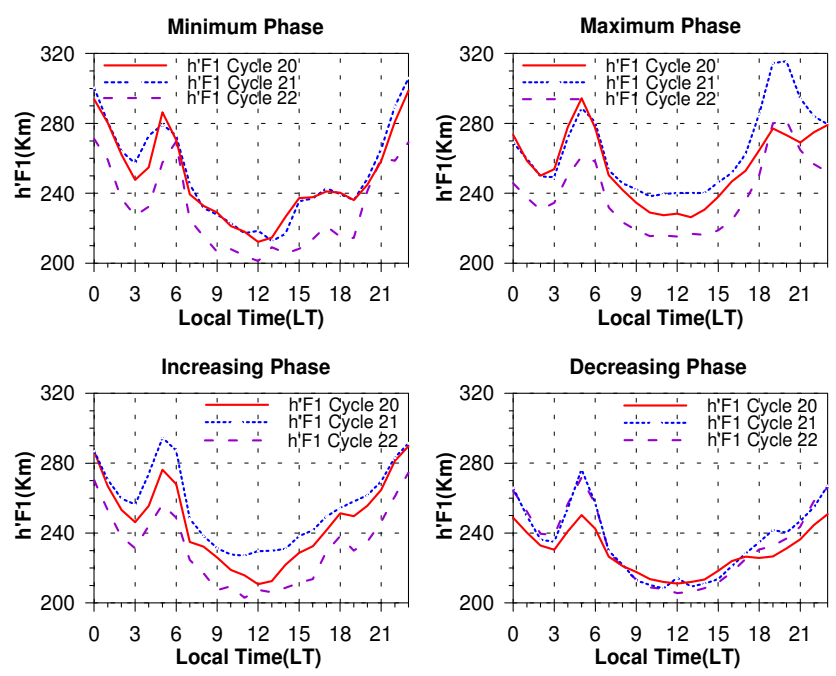

Fig. 11. Similar to Fig. 8 for $h^{\prime}$ F1.

sometimes the autumnal maximum is greater than the spring one (increasing phase of cycle 21 and 22 and maximum of cycle 22, see Fig. 4). But also the inverse behaviour could be found (minimum phase of cycle 20, decreasing phase of cycles 20 and 22, see Fig. 4).

The foF 2 semi annual variation is controlled by three mechanisms: (1) seasonal change of $\mathrm{O} / \mathrm{N}_{2}$ (Rishbeth and Setty, 1961; Rishbeth and Müller-Wodarg, 1999), (2) changes in the Sun-Earth distance (Yonezawa, 1959; Rishbeth et al., 2000a) and (3) the wave and tide forces transmitted to the thermosphere from the lower atmosphere (Zou et al., 2000). The asymmetry between the two equinoctial peaks results from the asymmetry of thermospheric parameters which influence the $f o \mathrm{~F} 2$ by neutral wind and composition (Balan et al., 1998). 
Table 5. Correlation coefficients and confidence intervals.

\begin{tabular}{ccc}
\hline $\begin{array}{c}\text { Critical } \\
\text { frequency }\end{array}$ & $\begin{array}{c}\text { Correlation } \\
\text { coefficients }\end{array}$ & $\begin{array}{c}99 \% \text { confidence } \\
\text { interval }\end{array}$ \\
\hline$f_{o \mathrm{~F} 2}$ & $0.842(20)$ & {$[0.760,0.897]$} \\
& $0.867(21)$ & {$[0.787,0.918]$} \\
& $0.842(22)$ & {$[0.753,0.900]$} \\
\hline \multirow{2}{*}{$f_{0 \mathrm{~F} 1}$} & $0.913(20)$ & {$[0.866,0.944]$} \\
& $0.724(21)$ & {$[0.574,0.827]$} \\
& $0.895(22)$ & {$[0.834,0.935]$} \\
\hline \multirow{2}{*}{$f_{0 \mathrm{E}}$} & $0.611(20)$ & {$[0.456,0.730]$} \\
& $0.745(21)$ & {$[0.607,0.839]$} \\
& $0.739(22)$ & {$[0.605,0.832]$} \\
\hline
\end{tabular}

We observe in Fig. 4 also some small indications of the winter anomaly of $\Delta f o \mathrm{~F} 2$ (smaller $\Delta f o \mathrm{~F} 2$ values in summer than in winter) during the maximum phase and the decreasing phase of solar cycles 20 and 22. This is related to winter maximum of $\mathrm{O}$ atoms, implying the relative increase of light gases above the winter hemisphere (Scialom, 1974), due to dynamic influences in the thermosphere (Rishbeth and Müller-Wodarg, 2006).

Ouattara et al. (2009) propose to explain the absence of the winter anomaly during cycle 20 by the influence of fluctuating wind stream activity.

$\Delta f o \mathrm{~F} 1$ (Fig. 5) exhibits a semiannual variation during the minimum phase of solar cycle 20 (top left panel) and an annual variation during the maximum phase of solar cycles 20 , 21 and 22 with a morning maximum (top right panel). During the increasing and decreasing phases of the sunspot cycle (bottom panels) $\Delta f o \mathrm{~F} 1$ exhibits a semiannual pattern, nevertheless the amplitude of the variation is small. This complex structure is not surprising because the F1-layer is the transition from the E-layer to the F2-layer, with a combination of both variations due to photochemical rates, and changes in atmospheric composition or temperature (Rishbeth and Kervin, 1968).

The annual variation of the $\Delta h^{\prime} \mathrm{F} 2$ (Fig. 6) results from the solar cycle variations of thermosphere winds (Rishbeth et al., 2000b).

\subsection{Diurnal variation}

The diurnal variation of $f o \mathrm{~F} 2$ (Fig. 8), exhibits the same pattern for all the phases of all the solar cycles, i.e. a minimum at 05:00 LT and a maximum at 14:00 LT. This is explained by the photochemical processes and the transport.

- foF1 diurnal variation (Fig. 9) has a maximum at 12:00 LT. This is explained by the control of the solar zenith angle (Rishbeth and Gariott, 1969). We can observe a large dispersion of this parameter during the decreasing phases of the three solar cycles (see bottom right panel of Fig. 9)

- $h^{\prime} \mathrm{F} 2$ diurnal variation has a maximum at 12:00 LT (Fig. 10). The dispersion is large for all the solar cycle phases, except the decreasing phases.

- $h^{\prime} \mathrm{F} 1$ diurnal variation (Fig. 11) exhibits a minimum near noon and the maximum near midnight. Other minima and maxima occur in the morning, at about 04:00 or 05:00 LT and at about 18:00 or 19:00 LT but the afternoon maximum is markedly smaller (except during the maximum phase of solar activity).

The different changes of $h^{\prime} \mathrm{F} 1$ and $h^{\prime} \mathrm{F} 2$ are attributed to temperature changes (Appleton, 1935; Lawden, 1969; Lejeune, 1972). Concerning the F1-layer it is due to its transition between the E-region where temperature oscillations are mainly semidiurnal, and the F2-region where the diurnal component prevails (Fontanari and Alcayde, 1974). The second peak of $h^{\prime} \mathrm{F} 1$ during maximum phase seems to be the well-known post sunset peak usually attributed to the ExB ionospheric electric field pulse (Fejer et al., 1979; Adohi et al., 2008).

\subsection{General conclusions}

The results from our ionosonde series provide the longest database ( 40 years) yet available on ionospheric layers variations at the northern tropical crest of ionization in the Asian longitude sector. This unique series of results is presented with abundant curves and tables.

The main characteristics of the ionospheric parameters observed at Phu Thuy are:

- The critical frequencies $f o \mathrm{~F} 2, f o \mathrm{~F} 1$ increase with solar cycle.

- The correlation coefficients between $f o \mathrm{~F} 2, f o \mathrm{~F} 1$, and $f o \mathrm{E}$ with solar sunspot number $\mathrm{Rz}$ are rather good but markedly smaller for foEs and virtual heights.

- The critical frequency $f o \mathrm{E}$ increases from solar cycle 20 to solar cycle 21 and then decreases during the decreasing phase of cycler 21 . The geomagnetic influence should be mentioned by an own point.

- The geomagnetic influence on mean values of different ionospheric parameters is very small at Phu Thuy as shown in Fig. 3.

- Seasonal variation of $\Delta f o \mathrm{~F} 2$ parameter shows semiannual, winter anomaly (the winter anomaly is only a small and not always detected phenomenon at Phu Thuy) and asymmetry between the two equinoctial peaks changing with the solar phases.

- The virtual heights of the F1 and F2 layers are highest in summer months. 
- The diurnal variation of $f o \mathrm{~F} 1$ exhibits one maximum around noon. The main features of $h^{\prime} \mathrm{F} 1$ are a minimum near noon and the maximum near midnight.

- The diurnal variation of $f o \mathrm{~F} 2$ exhibits a minimum at 05:00 LT and a maximum at 14:00 LT. $h^{\prime} \mathrm{F} 2$ has a maximum at 12:00 LT.

This work constitutes a starting point for the study of average variations. Further investigations with models are needed to explain all these characteristics, and particularly those related to the long term variations of the layers and the variations related to solar sunspot cycle phases.

Acknowledgements. The authors thank the Vietnam Academy of Science and Technology who provided ionospheric parameters data and the NGDC data centre for the values of sunspot number.

This work was financed by the "Laboratoire de Physique des Plasmas (LPP)", the Vietnam Ministry of Education and Training, and the French Centre National de Recherche Scientifique. The authors thank Paul and Gérard Vila for their English corrections.

Topical Editor K. Kauristie thanks A. G. Elias and another anonymous referee for their help in evaluating this paper.

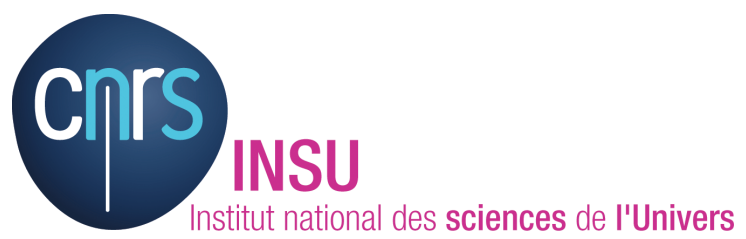

The publication of this article is financed by CNRS-INSU.

\section{References}

Adohi, B. J.-P., Vila, P. M., Amory-Mazaudier, C., and Petitdidier, M.: Equinox transition at the magnetic equator in Africa: analysis of ESF ionograms, Ann. Geophys., 26, 1777-1792, doi:10.5194/angeo-26-1777-2008, 2008.

Appleton, E. V.: Letters to the editor, Helley-Stewart Laboratory, King's College, London, England, 1935.

Balan, N., Bailey, G., J., and Jayachandran, B.: Ionospheric evidence for a nonlinear relationship between the solar e.u.v. and F10.7 cm fluxes during an intense solar cycle, Planet. Sci., 42(2), 141-145, 1993.

Balan, N., Otsuka, Y., Bailey, G., J., and Fukao, S.: Equinoctial asymmetries in the ionosphere and thermosphere observed by the MU radar, J. Geophys. Res., 103, 9481-9495, 1998.

Breit, G. and Tuve, M. A.: A Test of the existence of the conducting layer, Phys. Rev., 28, 554-575, 1926.

Bremer, J.: Long-term trends in the ionospheric E and F1 regions, Ann. Geophys., 26, 1189-1197, doi:10.5194/angeo-261189-2008, 2008.

Cnossen, I. and Richmond, A.: Modelling the effects of changes in the Earth's magnetic field from 1957 to 1997 on the ionospheric hmF2 and f0F2 parameters, J. Atmos. Solar-Terr. Phys., 70, 1512-1524, 2008.

Elias, A. G.: Trends in the F2 ionospheric layer due to long-term variations in the Earth's magnetic field, J. Atmos. Solar Terr. Phys., 71, 1602-1609, 2009.
Elias, A. G. and Ortiz de Adler, N.: foF2 long-term trends at the southern crest of the equatorial anomaly, Physics Chem. Earth, 31, 63-67, http://www.sciencedirect.com, 2006.

Farley, D. T.: The equatorial E-region and its plasma instabilities: a tutorial, Ann. Geophys., 27, 1509-1520, doi:10.5194/angeo-271509-2009, 2009.

Fejer, B. G., Farley, D. T., Woodman, R. F., and Calderon, C.: Dependence of equatorial $\mathrm{F}$ region vertical drifts on season and solar cycle, J. Geophys. Res., 84, 5792-5796, 1979.

Fontanari, J. and Alcayde, D.: Observation of neutral temperature tidal-type oscillations in the F1 region, Radio Sci., 9(2), 275280, 1974.

Lastovicka, J., Mikhailov, A. V., Ulich, T., Bremer, J., Alias, A. G., Ortiz de Adler, N., Jara, V., Abarca del Rio, R., Foppiano, A. J., Ovalle, E., Danilov, A. D.: Long-term trends in foF2: A comparison of various methods, J. Atmos. Solar Terr. Phys., 68, 1854-1870, 2006.

Lawden, M. D.: Problem associated with overlay analysis of F1region ionograms, J. Atmos. Terr. Phys., 31(1), 47-57, 1969.

Lejeune, G.: The coupling beween electron density and electron temperature in the daytime F-region, Ann. Geophys., 28, 15-20, 1972.

Mikhailov, A. V.: Ionospheric F1 layer long-term trends and the geomagnetic control concept, Ann. Geophys., 26, 3793-3803, doi:10.5194/angeo-26-3793-2008, 2008.

Mikhailov, A. V. and de la Morena, B. A.: Long-term trends of $f o \mathrm{E}$ and geomagnetic activity variations, Ann. Geophys., 21, 751760, doi:10.5194/angeo-21-751-2003, 2003.

Mikhailov, A. V. and Marin, D.: Geomagnetic control of the foF2 long-term trends, Ann. Geophys., 18, 653-665, doi:10.1007/s00585-000-0653-2, 2000.

Mikhailov, A. V. and Marin, D.: An interpretation of the $f o \mathrm{~F} 2$ and $h m \mathrm{~F} 2$ long-term trends in the framework of the geomagnetic control concept, Ann. Geophys., 19, 733-748, doi:10.5194/angeo19-733-2001, 2001.

Ouattara, F., Amory-Mazaudier, C., Fleury, R., Lassudrie Duchesne, P., Vila, P., and Petitdidier, M.: West African equatorial ionospheric parameters climatology based on Ouagadougou ionosonde station data from June 1966 to February 1998, Ann. Geophys., 27, 2503-2514, doi:10.5194/angeo-27-2503-2009, 2009.

Rishbeth, H. and Garriott, O. K.: Introduction to Ionospheric Physics, International Geophysics series, volume 14, 1969.

Rishbeth, H. and Kervin, C.: Seasonal changes displayed by F1layer ionograms, J. Atmos. Terr. Phys., 30(9), 1657-1665, 1968.

Rishbeth, H. and Müller-Wodarg, I. C. F.: Vertical circulation and thermospheric composition: a modelling study, Ann. Geophys., 17, 794-805, doi:10.1007/s00585-999-0794-x, 1999.

Rishbeth, H. and Müller-Wodarg, I. C. F.: Why is there more ionosphere in January than in July? The annual asymmetry in the F2-layer, Ann. Geophys., 24, 3293-3311, doi:10.5194/angeo-243293-2006, 2006.

Rishbeth, H. and Setty, C. S. G. K.: The layer at sunrise, J. Atmos. Terr. Phys., 20, 263-276, 1961.

Rishbeth, H., Müller-Wodarg, I. C. F., Zou, L., Fuller-Rowell, T. J., Millward, G. H., Moffett, R. J., Idenden, D. W., and Aylward, A. D.: Annual and semiannual variations in the ionospheric F2-layer: II. Physical discussion, Ann. Geophys., 18, 945-956, doi:10.1007/s00585-000-0945-6, 2000a. 
Rishbeth, H., Sedgemore-Schulthess, K. J. F., and Ulich, T.: Semiannual and annual variations in the height of the ionospheric F2-peak, Ann. Geophys., 18, 285-299, doi:10.1007/s00585-0000285-6, 2000b.

Scialom, G.: Neutral composition in the lower thermosphere, Radio Sci., 9(2), 253-261, 1974.

Yonezawa, T.: On the seasonal and non-seasonal annual variations and the semiannual variation in the noon and midnight densities of the F2 layerin middle latitudes II, J. Radio Res. Labs. Japan, 6, 651-668, 1959.
Zou, L., Rishbeth, H., Müller-Wodarg, I. C. F., Aylward, A. D., Millward, G. H., Fuller-Rowell, T. J., Idenden, D. W., and Moffett, R. J.: Annual and semiannual variations in the ionospheric F2-layer. I. Modelling, Ann. Geophys., 18, 927-944, doi:10.1007/s00585-000-0927-8, 2000. 